\title{
Biscuit e simulação 3D: unindo ciência e tecnologia às elucidações da origem da vida a partir da microbiologia
}

\author{
Cold porcelain and 3D simulation: joining science and technology to elucidate \\ the origins of life through microbiology
}

\author{
Aline Gonçalves De Andrade ${ }^{1}$, Gabriela Resende Netto ${ }^{2}$, Thyago Leal Calvo ${ }^{3}$, Jupyracyara Jandyra de \\ Carvalho Barros ${ }^{4}$
}

1 Licenciada. Universidade Federal de Goiás (UFG), Brasil. E-mail: alineandrade.goncalves@gmail.com

2 Licenciada. Universidade Federal de Goiás (UFG), Brasil. E-mail: gabrielanetto3@hotmail.com

3 Bacharel. Universidade Federal de Goiás (UFG), Brasil. E-mail: thyagoleal@yahoo.com

4 Docente. Universidade Federal de Goiás (UFG), Brasil. E-mail: jupyscbarros@hotmail.com

Recebido em: 31/03/2015 | Aprovado em: 29/10/2015

DOI: 10.12957/interag.2016.15862

\begin{abstract}
Resumo
A prática docente é fonte estimuladora à formação de cientistas, caso o período de permanência do estudante na escola seja aproveitado com dinamismo pelo professor-aluno nas diversas atividades STEM (Ciência, Tecnologia, Engenharia e Matemática). Contudo, antes de se formar cientista, esse precisa compreender sua formação enquanto humano e interações com o meio onde está inserido. Dessa forma, essa pesquisa objetivou oferecer aos discentes do Ensino Fundamental saberes e práticas de ciência e tecnologia como técnicas alternativas de ensino-aprendizagem para o esclarecimento quanto a gênese da vida a partir da teoria endossimbiótica. O estudo foi realizado com 31 escolares regularmente matriculados do $7^{\circ}$ ano do Ensino Fundamental, mas somente 18 participaram das entrevistas. As instituições envolvidas são da Cidade de Catalão - GO perímetro urbano e rural. Para as atividades pedagógicas foram empregados recursos audiovisuais, trabalhos manuais com massa de biscuit e animações em 3D para elucidar a teoria endossimbiótica. Os dados obtidos foram avaliados qualitativamente. Antes da oficina, todos escolares apresentaram-se inaptos em responder questões básicas sobre a biologia celular e tampouco sobre a evolução dos seres vivos. Após intervenção 72,2\% $(13 / 18)$ associaram a endossimbiose ao evento da gênese do eucarioto. Os debates em sala de aula junto aos escolares viabilizaram o aprimoramento dos sujeitos quanto às noções básicas de biologia celular, no qual esses demonstraram habilidade em articular saberes científicos acerca da evolução dos seres junto a estreita relação com o material pedagógico elaborado.
\end{abstract}

\begin{abstract}
Teaching practice is a stimulating source to a scientist's initial formation, in a scenario in which the student-teacher dynamically takes full advantage of the time spent in school in the several STEM activities (Science, Technology, Engineering and Mathematics). However, before becoming a scientist, he must understand his development as a human being and his interactions with the environment in which he is placed. In this way, this project aimed to offer knowledge and practice based on science and technology to pupils in Elementary School. The project would offer alternative techniques for the teaching/learning of the genesis of life sustained by the endosymbiotic theory. The study has been done with 31 twelve-year-old students, but only 18 participated in the interviews. The institutions involved are from Catalão, Goiânia, urban perimeter and countryside. Audiovisual resources, activities with cold porcelain clay and 3D animations were used for the pedagogical activities in order to elucidate the endosymbiotic theory. The data obtained were qualitatively analyzed. Before the workshop, all the students proved to be unfit when answering basic questions about cell biology and evolution of living beings. After the intervention, 72,2\% (13/18) associated endosymbiosis with the genesis of the eukaryote. The debates inside the classroom together with the pupils enabled their improvement in relation to the basic notions on cell biology. These students demonstrated their ability to articulate scientific knowledge about evolution together with the narrow relation with the pedagogical material elaborated.
\end{abstract}


Palavras-chave: Gênese da vida, STEM, Teoria

Endossimbiótica.

Keywords: Genesis of life, STEM, Endosymbiosis

theory.

Área temática: Educação.

Linha de extensão: Metodologias e estratégias de ensino/aprendizagem.

\section{Introdução}

A escola é o espaço propício à formação de futuros cientistas, devendo cada professor adquirir competências para instigar no escolar o interesse de imersão em alguma das áreas STEM (sigla, que em inglês refere-se à Ciência, Tecnologia, Engenharia e Matemática). Então, parte daí a necessidade da parceria universidade/escola pública para promover a difusão dos conhecimentos científicos. Todavia, para favorecer o processo de ensino/aprendizagem, os professores precisam realizar a transposição didática, ou seja, transformar o conhecimento científico em conhecimento escolar. ${ }^{1}$

É evidente que a intervenção pedagógica a ser aplicada na rotina escolar, deva propiciar o dinamismo do pensamento científico do aluno, e consequentemente, a busca de sua autonomia. ${ }^{2}$ Intervir junto aos escolares a fim de que estes reflitam de forma ativa face à problemática à qual são expostos, capacitando-os a debaterem questões de cunho sociocientíficas. Hamburger e colaboradores afirmam que, nesse processo, os aprendizes tornam-se aptos a discorrerem sobre temas científicos e sociais presentes no cotidiano. $^{3}$

Nesse sentido, diversas práticas educativas devem ser empregadas na Educação Básica para melhor compreensão do estudante nas atividades STEM. Em se tratando de Ciências, com ênfase nas discussões sobre a origem da vida, a oralidade aliada ao suporte visual são elementos pedagógicos interessantes os quais despertam o espírito crítico à formação do futuro cientista. ${ }^{4}$ Estudiosos como Silva e Paula ${ }^{5}$ e Reichmann e Schimin ${ }^{6}$ concordam que a ciência que estuda a origem da vida requer o uso constante de imagens. Pinheiro ${ }^{7}$ elucida que, a partir da imagem, os elementos textuais têm seu sentido ampliado ou especificado, tornando a compreensão mais produtiva.

Em sala de aula, geralmente as abordagens sobre gênese da vida são generalistas e deparam-se com questões de ordem filosófica, ideológica e teológica, dificultando o atendimento às dúvidas remanescentes por parte dos escolares quanto à temática. ${ }^{8}$

Refletir sobre a questão acima, não apenas esclarece a origem humana, como também explica as várias relações harmônicas e desarmônicas inerentes do ambiente em que o humano está inserido. Sob esse olhar, é possível compreender os caminhos da interação: humano e ambiente e a necessidade desse mesmo humano em apostar na Ciência para preservá-la.

\section{Da modelagem manual à computacional: explicando a teoria da endossimbiose}


O conceito de vida e suas interfaces são questões que permeiam as diversas fases do desenvolvimento humano, sendo foco principal dos eixos temáticos: "Origem da vida" e "Identidade dos Seres Vivos" como proposto pelo Currículo Referência para o Ensino de Ciências e Biologia.

Segundo Morin, citado por Costa $^{9}$, a diversidade e a complexidade de formas, comportamentos e interações no ambiente são importantes fatores os quais podem explicar a diversidade biológica do presente e do passado, o que é importante também para definir o humano da atualidade.

A Ciência Microbiologia é foco de intensos estudos, conforme a bióloga Lynn Margulis, em que os seres microscópicos possuem contribuição à história da humanidade. Essa estudiosa defende a teoria da endossimbiose, a qual explica que a célula eucariótica teria surgido da colonização harmônica (simbiose) de um microorganismo aeróbico por um anaeróbico, originando as mitocôndrias e cloroplastos. ${ }^{10}$

$\mathrm{Na}$ maioria das instituições de ensino, as abordagens sobre a Microbiologia como elemento importante de evolução dos seres vivos, geralmente é efetivada isenta de um planejamento teórico-metodológico dinâmico e reflexivo. Esse fato pode comprometer a compreensão dos escolares quanto à origem da vida, especificamente, o surgimento da espécie humana.

Diante da dificuldade de retratar ao escolar essa teoria, a confecção de modelos em massa de biscuit representa uma estratégia alternativa de ensino/aprendizagem, com custo relativamente baixo e de fácil aquisição. Por outro lado, Hennessy ${ }^{11} \mathrm{e}$ colaboradores afirmam que o uso de animações e simulações computadorizadas permite que o aluno visualize informações teóricas complexas e abstratas. Assim, ele é exposto ao conteúdo de forma objetiva, clara e não ambígua. Dessa forma, a utilização de animações em 2D ou 3D são importantes para a elucidação de processos científicos complexos e/ou moleculares, atuando como uma ponte entre o conhecimento científico e a abstração do aluno.

Face ao exposto, esse estudo teve como objetivo desenvolver técnicas alternativas de ensino-aprendizagem no Ensino Básico para compreensão da participação das células microbianas nos diversos eventos biológicos, bem como esclarecer as estratégias de adaptação dos seres vivos a partir da teoria endossimbiótica.

\section{Metodologia}

\section{Descrição geral do público-alvo}

Os sujeitos dessa pesquisa foram 31 discentes do $7^{\circ}$ Ano do Ensino Fundamental de duas instituições da rede pública, sendo a primeira localizada na área rural de Catalão GO, e a segunda localizada no âmbito urbano de Catalão - GO. A participação desses foi estabelecida pela apresentação do Termo de Consentimento Livre e Esclarecido TCLE devidamente assinado. De posse do termo de anuência do responsável pela instituição de ensino, foi consolidada a intenção desses em participar da pesquisa. As 
atividades foram realizadas durante as aulas de Ensino de Ciências, contando com a colaboração dos docentes responsáveis pelas disciplinas.

\section{Procedimentos, Estratégias e Ações}

Essa proposta foi estruturada a partir de uma dimensão emancipatória com o intuito de integrar saberes e práticas sobre as relações entre Ciência, Tecnologia, Sociedade e Ambiente - CTSA, com ênfase nas abordagens sobre a origem da vida e aspectos evolutivos.

Foi organizada uma oficina pedagógica, na qual foram aplicadas aulas expositivas, discussões em grupo após atividade laboratorial e trabalhos manuais.

Assim, inicialmente, a temática foi repassada aos escolares com auxílio de data show e uso de slides, preocupando-se em abordar temas sobre Fósseis; Evolução dos Seres e Seleção Natural; Adaptação e Teoria da Endossimbiose. Com uma semana de antecedência à exposição, um texto contendo as informações do tema ministrado era entregue aos escolares, de modo que eles pudessem se preparar previamente.

No laboratório de Ciências da escola participante, os alunos puderam se familiarizar com técnicas de colorações vitais para leveduras (que mantêm estável a atividade vital do micro-organismo) e fixadas para bactérias, as quais permitiam organizar os espécimes estudados em diferentes grupos: bactérias, fungos.

Ao término da oficina pedagógica, as verbalizações realizadas em sala de aula foram revividas a partir da elaboração, por parte do alunado, das etapas da teoria endossimbiótica empregando massa de biscuit, como estratégia pedagógica ao ensino de Ciências. ${ }^{12} \mathrm{O}$ conteúdo foi revisado, utilizando-se um esquema $3 \mathrm{D}$ animado produzido no software 3D Studio Max® versão 2011.

Todo material produzido pelos alunos ficou sob a responsabilidade da instituição participante, sendo cadastrado e descrito para posterior utilização. Todas as etapas foram registradas e organizadas em um portfólio para a escola.

É importante destacar que essa pesquisa caracterizou-se como uma investigação de cunho qualitativo, uma vez que os dados coletados foram frequentemente descritivos e obtidos a partir de entrevistas, de modo que fosse possível verificar a leitura de mundo dos sujeitos envolvidos: (1. Você sabe o que é Evolução? 2. O que é possível estudar na ciência Evolução? 3. Defina fósseis. 4. Qual a importância da adaptação para a sobrevivência dos seres vivos? 5. Qual a diferença de uma célula animal e vegetal, 6. Defina célula eucariótica e procariótica, 7. Explique a teoria da endossimbiose, explicando sua importância para a evolução dos seres vivos.

As respostas dos discentes foram lidas e, posteriormente, foram extraídos os excertos de cada frase em face de temática estudada. Esses, denominados de "unidades de significado" foram categorizados e comparados aos elementos semelhantes e frequência deles. ${ }^{13}$ 


\section{Resultados e Discussão}

A análise dos resultados foi realizada a partir das respostas fornecidas pelos discentes nas entrevistas. Em relação às questões propostas, os alunos apresentaram-se dispostos a discorrer sobre seus conhecimentos e a participarem da oficina pedagógica.

Dentre os 31 escolares regularmente matriculados no $7^{\circ}$ ano, somente 18 participaram da entrevista antes e após intervenção pedagógica (IP), uma vez que apresentaram, em tempo hábil, o termo de permissão dos seus responsáveis devidamente assinado. Os docentes destacaram que a falta de comprometimento dos alunos e/ou familiares é algo frequente, fato que tem prejudicado a implementação de práticas pedagógicas ao aprimoramento científico na rotina escolar. Os professores acrescentaram que essa situação por vezes acompanha o aluno até que este se exclua das atividades escolares até evadir-se da escola.

Desta forma, o grupo amostral para análise dos excertos foi constituído de 18 (100\%) participantes, sendo $27,7 \%$ (5/18), 72,2\% (13/18) do gênero feminino e masculino, respectivamente. Os participantes da escola da zona rural totalizaram em 7 escolares, sendo 42,8\% (3/7) do gênero feminino e $57,1 \%(4 / 7)$ do gênero masculino. Onze escolares do perímetro urbano participaram da oficina pedagógica, sendo 18,1\% (2/11) meninas e $81,8 \%(9 / 11)$ meninos.

De acordo com Driver ${ }^{14}$, avaliar o conhecimento prévio dos escolares é de extrema importância, pois assim é possível organizar melhor as estratégias de ensino para que desafiem as concepções iniciais dos alunos e que eles possam compreender o tema estudado.

Antes da intervenção pedagógica, quando questionados: "Você sabe o que é Evolução?" estavam inaptos a responder 72,2\% (13/18); após a intervenção pedagógica, 83,3\% $(15 / 18)$ dos discentes estavam aptos a responder tal indagação.

Quando os escolares foram indagados: "O que é possível estudar na ciência Evolução?” $83,3 \%(15 / 18)$ estavam inaptos a responder, mas após a intervenção pedagógica $100 \%$ $(18 / 18)$ estavam aptos a responder e todos os participantes envolveram os processos evolutivos com as adaptações que os seres vivos vão adquirindo de acordo com a evolução.

No que se refere à concepção dos escolares sobre fósseis, após intervenção pedagógica, foi possível organizar as respostas apresentadas pelos escolares, em 3 categorias: adaptação e evolução dos seres vivos; compreensão de hábitos/habitat dos seres vivos e registros históricos.

De acordo com Gadeá e Dorn ${ }^{15}$ quando os alunos fazem a associação entre os objetos e o seu cotidiano estimula a alfabetização e terão uma capacidade crítica mais desenvolvida. Abordar o ensino de Biologia, principalmente, no tocante à compreensão do cenário evolutivo baseado na ciência Microbiologia, empregando imagens e massas 
de modelar, por exemplo, pode representar uma estratégia metodológica eficiente à alfabetização científica. ${ }^{14}$ Essa afirmação tem sua relevância, principalmente quando se observa os exemplares confeccionados pelos estudantes a partir das explanações em sala de aula.

Ao serem questionados sobre: "Qual a importância da adaptação para a sobrevivência dos seres vivos?" foi possível observar que 72,2\% (13/18) não possuíam conhecimento prévio sobre o assunto. Entretanto, após intervenção, 88,8 \% (16/18) dos escolares demonstraram ter absorvido as informações, pois em seus discursos relacionaram com diversas estratégias à sobrevivência. Essa afirmação pode ser evidenciada nos discursos do sujeito 4:

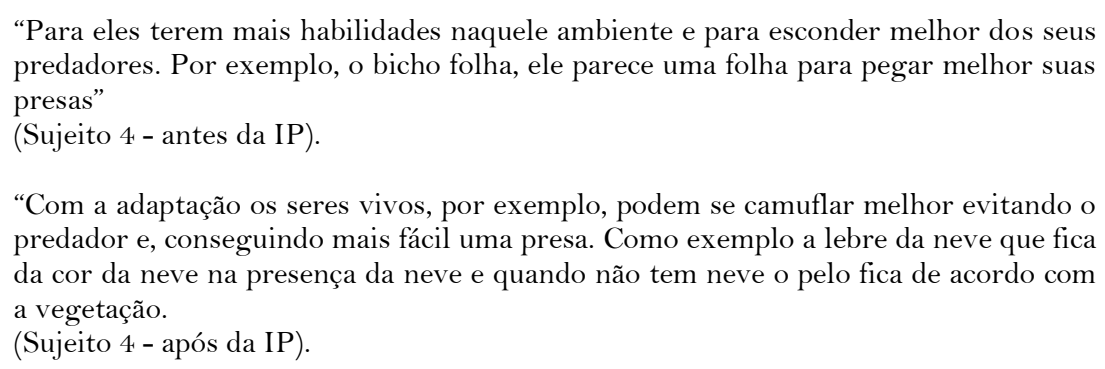

A utilização dos recursos visuais, nesse caso as imagens, proporcionou a $100 \%(18 / 18)$ dos escolares assimilarem o conhecimento sobre: "Qual a diferença de uma célula animal e vegetal?”.

Os diferentes métodos de ensino e aprendizado facilitam a construção do conhecimento. As crianças e jovens necessitam de novas metodologias que sejam atrativas e estimulantes para prender a atenção e facilitar o entendimento do conteúdo. ${ }^{1}$ De acordo com os autores Zômpero ${ }^{16}$ e Tauceda ${ }^{17}$, com as aulas práticas, demonstrativas ou experimentais os alunos conseguem interpretar melhor as informações, relacionam o conhecimento científico com o seu cotidiano e estimulam a curiosidade dos estudantes.

Durante esse estudo, aos escolares foi questionado: "Você sabe o que é uma célula eucariótica e uma célula procariótica?" 88,8\% (16/18) dos discentes estavam inaptos a responder, mas após a intervenção pedagógica 100\% (18/18) dos escolares demonstraram ter assimilado as informações quando afirmaram que a principal diferença entre a célula eucariótica e procariótica fundamenta-se na organização celular.

Segundo Margulis-Sagan, citado por Alves ${ }^{2}$, as mitocôndrias indicam a possibilidade dessas estruturas serem bactérias que, a partir de um processo simbiótico, hibernaram no interior de células bacterianas maiores.

Nesse estudo, antes da intervenção pedagógica foi evidente a incerteza dos estudantes em discutirem sobre a teoria da endossimbiose e qual a sua importância para a evolução. Contudo, após a oficina, 72,2\% (13/18) estavam aptos a associarem à gênese do eucarioto. Durante as explicações sobre o tema, o esquema $3 \mathrm{D}$ animado foi 
utilizado como uma estratégia de ensino/aprendizagem, permitindo aos escolares recriarem em massa de biscuit todas as experiências compartilhadas nas aulas expositivas, o que contribuiu ao entendimento dos discentes quanto ao surgimento dos seres vivos de maiores complexidades.

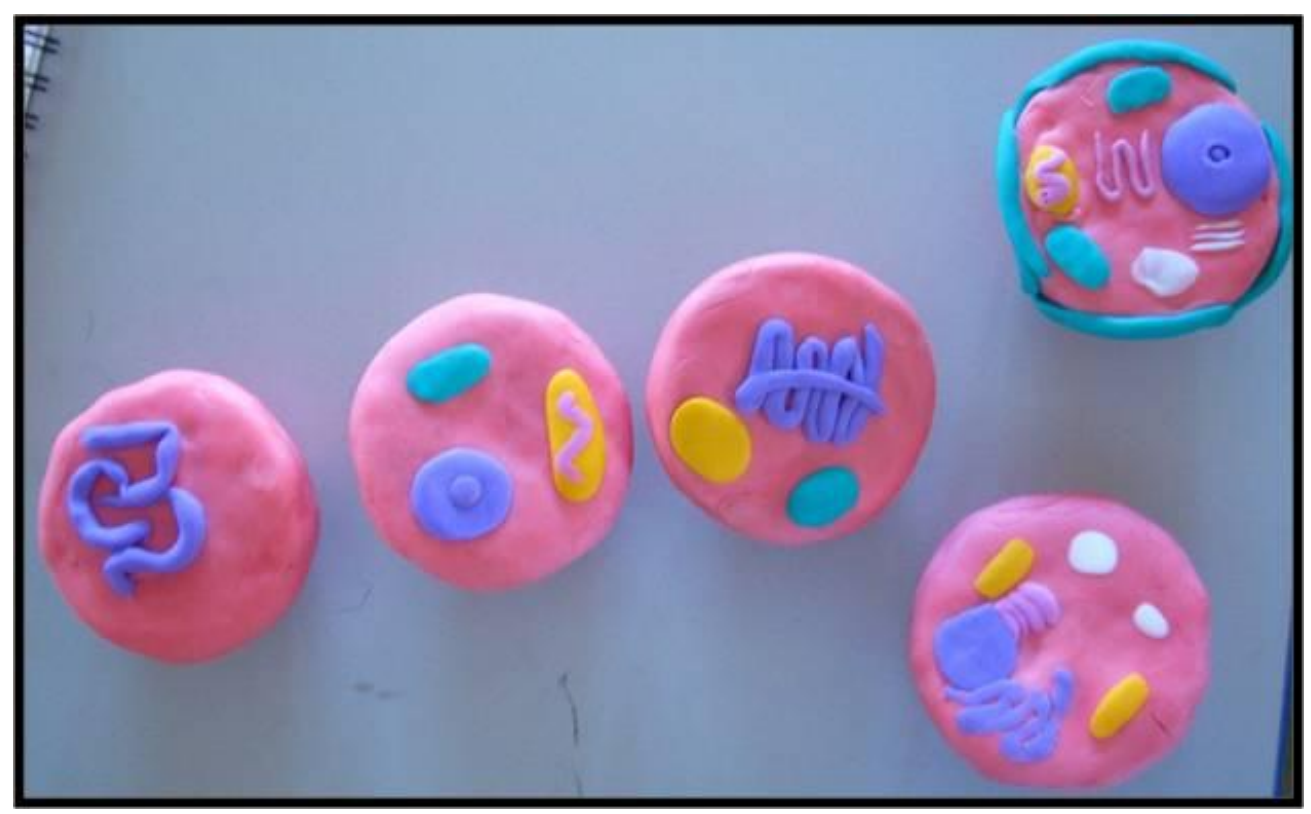

Figura 1. Fotodocumentação dos exemplares confeccionados em massa de biscuit pelos discentes do $7^{\circ}$ Ano do Ensino Fundamental de uma instituição da rede pública localizada na cidade de Catalão - GO representando a teoria da endossimbiose.

A oficina pedagógica estruturada e aplicada juntos aos escolares, por se fundamentar na coletividade e socialização de ideias, assegura o dinamismo, reflexão e contextualização do tema proposto. ${ }^{18,19}$ A estratégia metodológica utilizada também foi capaz de prover ações de extensão integradas ao ensino e pesquisa, com destaque ao desenvolvimento social e espírito crítico dos graduandos, docentes e técnicoadministrativos da Universidade Federal de Goiás, Regional Catalão (UFG/RC), a partir da prática da cidadania junto aos professores e escolares da Educação Básica pública.

A efetivação dessa proposta auxiliará os recursos pedagógicos já existentes empregados pelos docentes na Educação Básica no intuito de instigar os escolares sobre a gênese e evolução da vida.

\section{Conclusões}

Os dados obtidos na intervenção pedagógica permitem inferir que a aquisição do saber significativo face às questões apresentadas esteve intimamente associada à adoção de um planejamento teórico-metodológico, no qual o discente foi priorizado como coadjuvante na construção e apreensão do conhecimento. Ainda, a modelagem em biscuit e simulação computacional, alicerçadas em discussões científicas, asseguraram aos partícipes o aprimoramento dos saberes diante dos processos evolutivos fundamentando-se nos pressupostos da ciência Microbiologia. 


\section{Apoio}

- Programa de Iniciação Científica - Voluntária (PIVIC/UFG-RC)

\section{Financiamento}

- Programa Novos Talentos - CAPES - Edital nº 055/2012

- Programa de Cooperação Internacional STEM (Science, Technology, Engineering, Mathematics) - CAPES, Conselho Britânico/Fundo Newton - Edital nº6/2015.

\section{Contribuição dos autores}

A licenciada em Ciências Biológicas Aline G. Andrade foi responsável em organizar e efetivar a parte metodológica do referido trabalho.

O Termo de Esclarecimento Livre e Esclarecido e Anuência, bem como a realização das com as entrevistas e análise dos dados obtidos ficou sob a responsabilidade de Gabriela R. Netto.

A elaboração da animação em 3D ficou sob a responsabilidade do graduando em Bacharela em Ciências Biológicas Thyago L. Calvo.

Jupyracyara J. C. Barros idealizou a proposta extensionista e atuou como coordenadora da mesma.

\section{Referências}

1. ANTUNES, A. M.; SABÓIA-MORAIS, S. M. T. O jogo educação e saúde: uma proposta de mediação pedagógica no Ensino de ciências. Experiências em Ensino de Ciências. Goiânia: v. 5, p. 55-70, 2010.

2. ALVES, K. D.; BASTOS FILHO, J. B. Sobre as Relações Homem-Natureza a partir da desconstrução de Margulis de um ponto de vista de Popper. Experiências em Ensino de Ciências. Maceió: v.7, n. 1, p. 71-101, 2012.

3. HAMBURGER, E. W. et al.; O ensino de ciências e a educação básica: propostas para superar a crise. Academia Brasileira de Ciências. Rio de Janeiro, 2007.

4. VERGUEIRO, W. O uso das Histórias em Quadrinhos no ensino. In: RAMA (Org.). Como usar as histórias em quadrinhos em sala de aula. São Paulo: Contexto, 2005. 
5. SILVA, R. F.; PAULA, K. M. O corpo humano como instrumento de percepção do meio, Noções Básicas Sobre Anatomia Humana: ação pedagógica desenvolvida com alunos de ensino médio em uma escola pública estadual em Catalão-GO. Trabalho de Conclusão de Curso, Universidade Federal de Goiás, Catalão, 2010.

6. REICHMANN, D. R. X. T.; SCHIMIN, E. S. Imagens: contribuição para o ensino/aprendizagem em Biologia. Disponível em: <http://www.diaadiaeducacao.pr.gov.br/portals/pde/arquivos/10834.pdf?PHPS $\mathrm{ESSID}=2009050615332531>$ Acesso em: 06 de junho de 2012.

7. PINHEIRO, M. C. O. História em quadrinhos como ferramenta pedagógica. Revista Igapó, Manaus, v. 3, p. 11-17, 2009.

8. COSTA, L. O.; MELO, P. L. C.; TEIXEIRA, F. M. Reflexões acerca das diferentes visões de alunos do Ensino Médio sobre a origem da diversidade biológica. Revista Ciência e Educação. Rio de Janeiro: v. 17, n. 1, p. 115-128, 2011.

9. SAGAN, L. M. On the origin of mitosing cells. Journal of Theoretical Biology, [s.1], v.14, p. 225-274, 1967.

10. HENESSY, S. et al. Pedagogical approaches for technology-integrated science teaching. Computers e Education. v. 48, n. 1, p. 137-152, jan. 2007.

11. GOUVEIA, F. B. P.; CORREIA, E. S. Propostas para a prática de microbiologia utilizando recursos de baixo custo. Maiêutica Ciências Biológicas, v.1, n.1, p. 1921,2011

12. BARDIN, L. Análise de Conteúdo. 3. ed. Lisboa: Edições 70, 2004.

13. DRIVER, R. et al. Constructing scientific knowledge in the classroom. Educational Researcher, n. 7, p. 5-12, 1994. Tradução de MORTIMER, E. Construindo conhecimento científico em sala de aula. Química Nova na Escola, n. 9, p. 31-40, 1999.

14. GADEÁ, S. J. S.; DORN, R. C. Alfabetização Científica: pensando na aprendizagem de ciências nas séries iniciais através de atividades experimentais. Feira de Santana: p. 113-131, 2011.

15. FERREIRA, P. F.; JUSTI, R. S. Modelagem e o "fazer ciência”. Química Nova na Escola, São Paulo, n. 28, p. 32-36, maio 2008. 
16. ZÔMPERO, A. F.; PASSOS, A. Q.; CARVAlHO, L. M. Docência e as atividades de experimentação no ensino de ciências nas séries iniciais do ensino fundamental. Paraná, p. 43-54, 2012.

17. TAUCEDA, K. C.; NUNES, V. M.; DEL PINO, J. C. A epistemologia/metodologia do aluno pesquisador na educação em ciências. Experiências em Ensino de Ciências: Porto Alegre: v. 6, p. 133-141, 2011.

18. BUOGO, A. L. et al. Oficinas Pedagógicas: experiências para qualificar a ação docente. In: IV Encontro Ibero-Americano de Coletivos Escolares e Redes de Professores que fazem Investigação na sua Escola, Lajeado, 2005.

19. MOITA, F. M. G. S. C.; ANDRADE, F. C. B. O saber se mão em mão: A oficina pedagógica como dispositivo para a formação docente e a construção do conhecimento na escola pública. In: Educação, Cultura e Conhecimento na contemporaneidade: desafios e compromissos, 2006. Caxambu. Anais... Caxambu: ANPED, 2006. 